\title{
Leprosy chemoprophylaxis in Micronesia
}

\author{
C. DILETTO* \& L. BLANC** \\ (PRESENTED BY L. LEVY) \\ *Western Pacific Regional Office of the World Health Organization, \\ Manila, The Philippines, and **World Health Organization, Geneva, \\ Switzerland
}

\begin{abstract}
Summary A programme of chemoprophylaxis was introduced as a component of the leprosy control programme in the Federated States of Micronesia (FSM), beginning in 1996. The entire population of the country was to be screened, and a single dose of $600 \mathrm{mg}$ rifampicin, $400 \mathrm{mg}$ ofloxacin and $100 \mathrm{mg}$ minocycline (ROM) was to be administered to the entire population. Two rounds of screening the entire population were carried out, approximately 1 year apart, and chemoprophylaxis was administered at the time of each screening. Ninety percent of the population were screened at least once, and $55 \%$ were screened in both rounds; $87 \%$ of the population received at least one dose, and 54\% received two doses. In the course of the first round, 322 new cases were detected, whereas only 80 new cases were detected during the second round, of whom only 12 had received chemoprophylaxis in the course of the first round. A third round of screening, confined to a small number of villages in both Chuuk and Pohnpei, in which states leprosy endemicity was high, was carried out approximately 2 years after the second. Only 16 new cases were detected during the third round of screening, whereas 102 new cases had been detected in this same population during the first round of screening, and 32 new cases during the second. Six of the 16 newly detected cases stated that they had been administered chemoprophylaxis at least once; however, this information may not be reliable.
\end{abstract}

Because of the continuing high prevalence of leprosy and the failure of new-case detection rates to fall, programmes of chemoprophylaxis were introduced as a component of the leprosy control programs in three island nations in the Pacific Ocean: the Federated States of Micronesia (FSM), Kiribati and the Republic of the Marshall Islands (RMI). These three countries consist of many atolls and small islands scattered over millions of square miles in the central and western portions of the Pacific Ocean. Some of the atolls are unpopulated, and others support only very small populations. Distances are enormous, transportation among outlying islands is often unreliable, and access to many of them is difficult. In addition, these are very small countries in terms of their populations; the population of the FSM, the largest of the three, was slightly greater than 100,000, according to a census carried out in 1994.

In these three countries, entire populations were to be screened, and chemoprophylaxis, consisting of a single dose of $600 \mathrm{mg}$ rifampicin, $400 \mathrm{mg}$ ofloxacin and $100 \mathrm{mg}$ minocycline (ROM), was to be administered either to the entire population (FSM) or to the populace of the largest, most endemic islands (Kiribati), or limited to household contacts (RMI). Children under 15 years of age were to be administered rifampicin only. The second round of screening has not been completed in Kiribati, and the first round has not yet been completed in the RMI, 
Table 1. Screening in the FSM

\begin{tabular}{|c|c|c|c|c|c|c|}
\hline \multirow[b]{2}{*}{ State } & \multirow{2}{*}{$\begin{array}{c}1994 \\
\text { population }\end{array}$} & \multicolumn{2}{|c|}{ Numbers screened } & \multicolumn{2}{|c|}{$\begin{array}{c}\text { Administered } \\
\text { chemoprophylaxis }\end{array}$} & \multirow{2}{*}{$\begin{array}{c}\text { Numbers receiving } \\
\text { two doses }\end{array}$} \\
\hline & & 1 st round & 2 nd round & 1 st round & 2 nd round & \\
\hline Pohnpei & 33,692 & 22,303 & 23,844 & 20,993 & 23,323 & 14,221 \\
\hline Chuuk & 53,319 & 41,718 & 40,933 & 40,849 & 40,295 & 34,603 \\
\hline Yap & 11,178 & 7669 & 6951 & 7571 & 6893 & 5314 \\
\hline Kosrae & 7317 & 4176 & 5471 & 4103 & 5354 & 2996 \\
\hline Total & 105,506 & 75,866 & 77,199 & 73,516 & 75,865 & 57,134 \\
\hline
\end{tabular}

whereas the programme in the FSM was begun in 1996 and completed 2 years ago, so that meaningful data are available.

In the FSM, two rounds of screening the entire population were carried out, approximately 1 year apart, and chemoprophylaxis was administered at the time of each screening. As shown in Table 1, 90\% of the population were screened at least once, and $55 \%$ were screened in both rounds; $87 \%$ received at least one dose of chemoprophylaxis, and $54 \%$ of the population received two doses.

The numbers of new cases of leprosy detected in the course of the first two rounds are examined in Table 2. Of particular interest is that, of the 80 new cases detected during the second round, only 12 had been administered chemoprophylaxis in the course of the first round. Thus, the relative risk of clinically evident disease among those administered chemoprophylaxis was 0.058 that among those not treated earlier. It is clear that the great majority of the 68 new cases detected among those who had not received prophylaxis had not been screened during the first round, and some of these may represent 'backlog cases', i.e. their disease pre-existed the programme. (This programme was described in a series of papers presented at the Workshop on Prevention of Leprosy, held in Pohnpei, FSM 25-27 May 1999, and published in a supplement to the December 1999 number of the International Journal of Leprosy.)

Mass screening is very expensive. Because the populations of two of the states of the FSM, Kosrae and Yap, are very small (total $<20,000$ ), and a total of only 22 patients had been

Table 2. New-case detection in the FSM

\begin{tabular}{lrrrrr}
\hline & Pohnpei & Chuuk & Yap & Kosrae & Total \\
\hline $\begin{array}{l}\text { lst round } \\
\text { Total }\end{array}$ & 153 & 148 & 10 & 11 & 322 \\
PB & 127 & 112 & 7 & 9 & 255 \\
MB & 26 & 36 & 3 & 2 & 67 \\
Children $<15$ years & 50 & 61 & 1 & 4 & 116 \\
2nd round & & & & & \\
Total & 26 & 53 & 0 & 0 & 30 \\
Single lesion & 11 & 27 & 0 & 0 & 14 \\
PB & 4 & 10 & 0 & 1 & 28 \\
MB & 11 & 16 & 0 & 0 & 31 \\
Children $<15$ years & 5 & 26 & 0 & & \\
& & & & & \\
\hline
\end{tabular}


Table 3. Results of screening in several high-prevalence villages in the FSM

\begin{tabular}{|c|c|c|c|c|c|c|c|}
\hline \multirow[b]{2}{*}{ State/village } & \multirow[b]{2}{*}{$\begin{array}{c}1994 \\
\text { census }\end{array}$} & \multicolumn{3}{|c|}{ Number screened } & \multicolumn{3}{|c|}{ Number of new cases } \\
\hline & & $\begin{array}{l}1 \mathrm{st} \\
\text { round }\end{array}$ & $\begin{array}{l}2 \text { nd } \\
\text { round }\end{array}$ & $\begin{array}{l}\text { 3rd } \\
\text { round }\end{array}$ & $\begin{array}{c}1 \mathrm{st} \\
\text { round }\end{array}$ & $\begin{array}{l}\text { 2nd } \\
\text { round }\end{array}$ & $\begin{array}{l}\text { 3rd } \\
\text { round }\end{array}$ \\
\hline Chuuk & 9609 & 7894 & 7508 & 7511 & 64 & 26 & 6 \\
\hline Wichap/Weno & 1446 & 1203 & 818 & 1189 & 16 & 4 & 1 \\
\hline Nepukos/Weno & 2932 & 2976 & 2857 & 2713 & 9 & 4 & 3 \\
\hline Kuchua/Tonoas & 936 & 650 & 491 & 456 & 6 & 3 & 0 \\
\hline Pollap & 710 & 476 & 503 & 508 & 3 & 3 & 1 \\
\hline Houk & 494 & 429 & 469 & 485 & 7 & 2 & 0 \\
\hline Foup/Tolensom & 963 & 562 & 802 & 528 & 3 & 4 & 1 \\
\hline Nama & 881 & 680 & 826 & 878 & 13 & 6 & 0 \\
\hline Fason/Tolensom & 827 & 510 & 388 & 414 & 3 & 0 & 0 \\
\hline Foupo/Tolensom & 420 & 408 & 354 & 340 & 4 & 0 & 0 \\
\hline Pohnpei & 2740 & 1951 & 1832 & 2014 & 38 & 6 & 10 \\
\hline Kepin/Sohkes & 133 & 207 & 249 & 191 & 4 & 1 & 1 \\
\hline Kepira/Sohkes & 460 & 486 & 343 & 465 & 15 & 2 & 2 \\
\hline Metipw/Madolen & 234 & 261 & 144 & 222 & 9 & 0 & 0 \\
\hline Porakied/Kolonia & 1218 & 471 & 664 & 720 & 3 & 3 & 6 \\
\hline Paiel/Kitti/Sohkes & 458 & 254 & 308 & 281 & 3 & 0 & 1 \\
\hline Pahlap/Uh & 237 & 272 & 124 & 135 & 4 & 0 & 0 \\
\hline Total & 12,349 & 9845 & 9340 & 9525 & 102 & 32 & 16 \\
\hline
\end{tabular}

detected in both states, the decision was taken to assess the results of the programme of chemoprophylaxis by a third round of screening confined to a small number of villages of high endemicity in both Chuuk and Pohnpei. In fact, these villages accounted for more than $30 \%$ of the new cases detected during the first round of screening and for $40 \%$ of the cases detected during the second round. As shown in Table 3, only 16 new cases were detected during the third round of screening, whereas 102 new cases had been detected in this same population during the first round of screening, and 32 new cases during the second. Of the 16 new cases, six (all from Pohnpei) stated that they had been administered chemoprophylaxis at least once; however, this information is based only on the patients' statements, and may not be reliable.

The decrease in the number of new cases between the first and the second rounds of screening in these selected villages (approximately 67\%) is not greatly different from that in the FSM as a whole (approximately 75\%). Because much if not all of this decrease may have resulted simply from the discovery, in the course of the first round, of a relatively large proportion of old, previously unknown patients, it cannot be attributed to the effects of screening and chemoprophylaxis. However, it is different to attribute the continued decline in these selected villages of the number of new cases between the second and the third rounds of screening entirely to the discovery, during the second round, of additional backlog patients.

However, even assuming that the decrease between the second and the third rounds represents an effect of the programme of screening and chemoprophylaxis, in the absence of a group that had been administered a placebo, one cannot attribute the decline of the new-case detection rate to the chemoprophylaxis. It may be that intensive screening and immediate treatment of the newly discovered patients would have resulted in a similar decline, even had chemoprophylaxis not been administered. 


\section{DISCUSSION}

Professor Grosset: Among the 32 new patients detected during the second round of screening and the 16 detected during the third round, how many had not received chemoprophylaxis?

Professor Levy: Six of the 16 new patients detected during the third round of screening stated that they had received chemoprophylaxis. However, these are very 'soft' data. No information with respect to prior doses of chemoprophylaxis is available for the 32 patients detected during the second round.

Professor Grosset: I invite you to speculate. What would you conclude, if you could be certain that the six had indeed received chemoprophylaxis?

Professor Levy: I can't answer your question, even to speculate, because the denominators are different. Sixteen people of a total of 9525 examined were found to have leprosy. However, we don't know what proportion of the total had received earlier chemoprophylaxis. Assuming that as large a proportion of this population had received chemoprophylaxis on at least one prior occasion as had in the entire population of the FSM, the denominators differ greatly. If you recall, the finding in the course of the second round of 80 new cases, most of whom had not received chemoprophylaxis in the course of the first round, represented a substantial decrease of relative risk, because the number who had not been administered chemoprophylaxis was very much smaller than the number of those who had.

Dr Noordeen: I believe that the key question is the following: 'If people to whom chemoprophylaxis had been administered developed leprosy, what is the explanation?' I believe that the explanation is that chemoprophylaxis can be $100 \%$ effective only if coverage of the leprosy patients in the community with chemotherapy is $100 \%$. Chemoprophylaxis can have only a very transitory effect, and, after the effect has waned, and as long as transmission of the organism can occur, the individual can immediately be infected with $M$. leprae and subsequently become ill with leprosy. One may imagine that coverage of leprosy patients with chemotherapy was less than $100 \%$.

Professor Levy: I believe that there is an additional explanation. Among those already infected with $M$. leprae who were administered chemoprophylaxis, the infection nevertheless progressed, and they became ill.

Dr Klatser: This was my question as well. Simply put, is a single dose of ROM sufficient to eradicate infection with $M$. leprae?

Professor Levy: If I remember correctly, at the time this programme was planned, trials of ROM had already begun, and although these trials were still in their infancy, there was some information that ROM was efficacious to some degree. We now know that a single dose of ROM is almost as efficacious in the treatment of single-lesion leprosy as 6 months of standard MDT for PB leprosy. We assume that the population of M. leprae among the 'inapparently' infected is no larger than that among patients with single-lesion leprosy, and, therefore, we expect the same degree of efficacy.

Dr Saunderson: Would you describe the case-finding activities before the programme, and those to be carried out in the future?

Professor Levy: The intensity of case finding prior to the programme differed greatly from that carried out in the course of the programme. In the course of the first two rounds of screening, the attempt was made to screen the entire population, and to administer chemoprophylaxis to the entire population. Prior to this programme, what screening had been carried out was not at this level of intensity. For the future, screening the entire population will not be considered. However, I suppose it will be possible to persuade WPRO 
and the local authorities to carry out a fourth round of screening in these highly endemic villages.

Dr Sow: Had BCG been employed in this population? And were the new cases primarily those with single lesions?

Professor Levy: As I remember, BCG had been used in this population. However, the intensity with which a programme of vaccination with BCG had been pursued varied greatly from state to state within the FSM. I don't believe that it is possible to determine at this time who had been administered BCG and who had not. With respect to your second question, we have information regarding single-lesion leprosy only from the second round; as I have shown, nearly half of the patients newly detected during the second round presented single lesions.

Professor Grosset: Can you identify the types of leprosy with which the 16 new patients detected in the course of the third round presented? If, in fact, many of these patients exhibited MB leprosy, this would immediately explain the failure of chemoprophylaxis.

Dr van Brakel: Can you explain the decrease of the proportion of the population screened in the course of the second and third rounds. Isn't there the risk that a substantial number of patients were missed in the non-screened portion of the population?

Professor Levy: In fact, the proportion of the population screened in each round was rather large.

Dr van Brakel: However, your table showed that only $55 \%$ of the population was screened in both the first and second rounds.

Professor Levy: It is for this reason that two rounds of screening were planned. It was understood that, at the time of the first round, some of those normally resident would be away from their homes. Also, it is important to note that the population figures shown are those of a census carried out in 1994. Had another census been carried out in 1996, the expected population might have been smaller. Also, substantial numbers of Micronesians reside in Guam, Hawaii and the continental US, with relatively free movement back and forth. In fact, the population was screened as completely as possible.

Professor Grosset: My conclusion from this paper and the subsequent discussion is that now, a very careful trial of chemoprophylaxis must be carried out. 